\title{
CORRESPONDENCE
}

Correspondents are asked to be brief

Specialist Training in Medicine

SIR,-I would be most grateful to use your correspondence columns to make a report on the progress of the approval of training posts for higher specialist training.

We now have had a considerable number of applications for visits to training posts Some visits have already been made and it is hoped to make an intensive effort in the first half of 1974. In an earlier announcement (23 June, 1973, p. 724) it was made clear that posts suitable for general professional training would not be visited by the Joint Committee on Higher Medical Training. These posts are being dealt with in Scotland by the Scottish Council for Postgraduate Medical Education and in England, Wales, and Northern Ireland by the Roya College of Physicians of London. We realize that there is still some misunderstanding about the difference between the two kinds of

\section{Screening for Cervical Cancer}

SIR,-I read with considerable anticipation and interest your leading article on the "Uncertainties of Cervical Cytology" (1 December, p. 501), but came to the conclusion that it was out of date.

Most gynaecologists and cytologists now agree that screening for in situ cervical carcinoma can lower the rate of invasive disease and eventually the mortality. ${ }^{1}$ Professor E. G. Knox in his paper "The Epidemiologist"2 described his computer simulations and found that screening programmes are worthwhile. Surely the fall in the standardized mortality rates from cancer of the cervix at ages 45-64 years since 1965, reported recently from British Columbia, is what would be expected if screening is effective?

The fall in incidence of this disease reported from Aberdeen ${ }^{4}$ continues and there has been a fall in mortality rate,,$^{5}$ which is three times greater than the average fall reported in England and Wales. This fall is mainly attributed to the removal of the cases of micro-invasive preclinical cancers rather than to the removal of carcinoma-in-situ which, because of its slow progression, will affect the death rates only later. There is certainly no "increasing tendency for total hysterectomy to replace cone-biopsies as therapy" in this region.

Well-organized screening which covers all social groups on a systematic basis and does not rely only on the women asking for the test is difficult to organize, but it can be done $^{6}$; the fact that the ensuing fall in incidence and mortality follows so naturally strongly suggests that its systematic use is the main causal factor.-I am, etc.,

J. ElizABETH MACGREgor Departments of Obstetrics and Gynaecology and

University of Aberdeen post. Recognition of posts for higher medical training will usually be made at senior registrar level. The numbers of these posts are related by the Departments of Health to the anticipated number of consultant vacancies, but a small number of registrar posts may be considered for recognition, provided that the training programme available meets the necessary requirements for the specialty as described in the Joint Committee's first report ${ }^{1}$ published in October 1972.-I am, etc.,

Cyril A. Clarke Chairman, Executive Committee,
Joint Committee on Higher Medical Training

Royal College of Physicians,
London N.W.1

1 Joint Committee on Higher Medical Training First Report. London, J.C.H.M.T. at the Roya College of Physicians, 1972. test and had M.I.C.s with long trailing endpoints as first described by Professor May and Mrs. Davies (12 August 1972, p. 376). The remaining strains were sensitive.-We are, etc.,

B. Cornere

R. MENZIES

Microbiology Department,

Green Lane Hospital,

1 Ericsson, H. M., and Shernis, J. C., Acta Pathologica et Microbiologica Scandinavica Section, $B, 1971$, Supple. No 217. p. 67

\section{Chemotherapy of Disseminated} Malignant Tumours

SIR,-Price and Goldie ${ }^{1}$ reported encouraging results in the treatment of various disseminated solid malignant tumours with multiple antitumour drugs. Complete or partial tumour regression was observed in 20 of their 40 patients, including three out of five with lung carcinoma.

We have now treated 17 patients with bronchial carcinoma in the Dundee Chest Service with schedule I of this regimen, using cyclophosphamide, fluorouracil, actinomycin $\mathrm{D}$, vincristine, methotrexate and cytosine arabinoside. The diagnosis was confirmed histologically in 14 patients. In the remaining three the clinical and $x$-ray findings and progress were in keeping with disseminated malignant disease. The histology of the tumours was as follows: oat cell, 5; poorly differentiated or anaplastic, 5; adenocarcinoma, 2; and squamous cell, 2 . In all but one of these patients there was evidence of dissemination of tumour. Four patients had had previous intravenous cyclophosphamide to a total of $4 \mathrm{~g}$. in each case. One had had additional oral cyclophosphamide for three months. Six patients had had previous radical but conventional radiotherapy. The number of treatments with the multiple cytotoxic regimen varied in individual cases from one to five, average two. In one patient mustine was substituted for cyclophosphamide but this was the only deviation from the prescribed regimen.

At the time of writing there are only three survivors, who started treatment four, five, and six months ago respectively. In the remaining 14 cases the average time from first treatment to death was $2 \frac{1}{2}$ months. In only one patient was there good evidence of clinical improvement (reduction in size of skin nodules). Ignoring fluctuating changes in chest radiographs there has been no evidence of radiological improvement. In keeping with the original report, the regimen has been well tolerated, the only side effects noted by our patients being significant alopecia in two cases (both in women) and vomiting in only one. Peripheral blood examination including leucocyte and platelet counts at two weeks after treatment commonly showed some leucopenia, but no serious blood dyscrasia was recorded.

fhe one already descril and three strains (isolated than once) which were resistant to the disc 